\title{
Insulin-Like Growth Factor-1 Inhibits Adult Supraoptic Neurons via Complementary Modulation of Mechanoreceptors and Glycine Receptors
}

\author{
Jeanne Ster, ${ }^{\star}$ Claude Colomer, ${ }^{\star}$ Cécile Monzo, Anne Duvoid-Guillou, Françoise Moos, Gérard Alonso, and \\ Nicolas Hussy \\ Biologie des Neurones Endocrines, Centre National de la Recherche Scientifique (CNRS) Unité Mixte de Recherche 5101, Centre CNRS Institut National de \\ la Santé et de la Recherche Médicale de Pharmacologie et d’Endocrinologie, 34094 Montpellier Cedex 5, France
}

\begin{abstract}
In the CNS, insulin-like growth factor-1 (IGF-1) is mainly known for its trophic effect both during development and in adulthood. Here, we show than in adult rat supraoptic nucleus (SON), IGF-1 receptor immunoreactivity is present in neurons, whereas IGF-1 immunoreactivity is found principally in astrocytes and more moderately in neurons. In vivo application of IGF-1 within the SON acutely inhibits the activity of both vasopressin and oxytocin neurons, the two populations of SON neuroendocrine cells. Recordings of acutely isolated SON neurons showed that this inhibition occurs through two rapid and reversible mechanisms, both involving the neuronal IGF-1 receptor but different intracellular messengers. IGF-1 inhibits $\mathrm{Gd}^{3+}$-sensitive and osmosensitive mechanoreceptor cation current via phosphatidylinositol-3 (PI3) kinase activation. IGF-1 also potentiates taurine-activated glycine receptor (GlyR) $\mathrm{Cl}^{-}$currents by increasing the agonist sensitivity through a extremely rapid (within a second) PI3 kinase-independent mechanism. Both mechanoreceptor channels and GlyR, which form the excitatory and inhibitory components of SON neuron osmosensitivity, are active at rest, and their respective inhibition and potentiation will both be inhibitory, leading to strong decrease in neuronal activity. It will be of interest to determine whether IGF-1 is released by neurons, thus participating in an inhibitory autocontrol, or astrocytes, then joining the growing family of glia-to-neuron transmitters that modulate neuronal and synaptic activity. Through the opposite and complementary acute regulation of mechanoreceptors and GlyR, IGF-1 appears as a new important neuromodulator in the adult CNS, participating in the complex integration of neural messages that regulates the level of neuronal excitability.
\end{abstract}

Key words: insulin-like growth factor 1; taurine; mechanoreceptor; osmoregulation; astrocyte; neuroendocrine cells

\section{Introduction}

Insulin-like growth factor-1 (IGF-1) is a pleitropic factor with a wide spectrum of functions. It acts via a high-affinity IGF-1 receptor linked to tyrosine kinase activity and various intracellular messenger cascades such as phosphatidylinositol-3 (PI3) kinase and MAP kinases. In the CNS, IGF-1 is principally known for its action on cell proliferation, differentiation, and survival during development (de Pablo and de la Rosa, 1995; O'Kusky et al., 2000) and in the adult (Brooker et al., 2000; Aberg et al., 2003). Synthesized mainly in the liver and other peripheral organs, IGF-1 crosses the blood-brain barrier (Reinhardt and Bondy, 1994) and is found at a high level in CSF (Carro et al., 2000).

\footnotetext{
Received Sept. 30, 2004; revised Jan. 11, 2005; accepted Jan. 13, 2005.

This work was supported by the Centre National de la Recherche Scientifique. We are grateful to David Poe for kindly providing the VP and OT antibodies and to Isabel Lefèvre for her expert advice.

*J.S. and C.C. contributed equally to this work.

Correspondence should be addressed to Nicolas Hussy, Dynamique des Réseaux Neuronaux, Institut National de la Santé et de la Recherche Médicale, U704, Unité de Formation et de Recherche de Biologie, Bāt B, 2280 rue de la Piscine, Boîte Postale 53, 38041 Grenoble Cedex 9, France. E-mail: nicolas.hussy@ujf-grenoble.fr.

J. Ster's and C. Colomer's present address: Centre National de la Recherche Scientifique (CNRS)-Unité Propre de Recherche 2580, Centre CNRS Institut National de la Santé et de la Recherche Médicale de Pharmacologie et d'Endocrinologie, 141 rue de la Cardonille, 34094 Montpellier Cedex 5, France.

D0I:10.1523/JNEUROSCI.4053-04.2005

Copyright $\odot 2005$ Society for Neuroscience $\quad$ 0270-6474/05/252267-10\$15.00/0
}

IGF-1 is also expressed in the CNS (Labourdette and Sensenbrenner, 1995). If expression of IGF-1 receptor in the CNS is high during postnatal development, it decreases in adulthood and only persists at moderate levels in specific brain regions (Zhou et al., 1999). In addition to its implication in neurogenesis in hippocampus (Trejo et al., 2001; Aberg et al., 2003), the function of IGF-1 in adult brain stays mostly unclear.

The hypothalamo-neurohypophysial system (HNS) is one adult CNS area where IGF-1 could be of significant importance. The HNS consists of vasopressin (VP) and oxytocin (OT) neurons located in the supraoptic nucleus (SON) and paraventricular nucleus, which send their axons in the neurohypophysis where they release the neurohormones in the blood circulation. A major role of the HNS is the regulation of body fluid balance through the modulation of VP and OT release according to changes in plasma osmotic pressure. An important part of this regulation implies the osmosensitivity of SON neurons, which involves two complementary systems (Bourque, 1998; Hussy et al., 2000; Voisin and Bourque, 2002). First, neurons express specific mechanoreceptors, active at rest, that are inhibited by cell swelling occurring during hypotonic stimulus and activated by cell shrinking induced by hypertonicity (Oliet and Bourque, 1994; Bourque, 1998). Second, neighboring astrocytes release 
taurine at a slow rate to activate extrasynaptic neuronal glycine receptors (GlyRs), thereby imposing a tonic inhibitory influence (Hussy et al., 2000; Hussy, 2002). Taurine release is enhanced by hypotonicity and suppressed under hypertonic conditions. These two mechanisms act in concert to finely modulate neuronal activity (Hussy et al., 2000; Voisin and Bourque, 2002). IGF-1 immunoreactivity and mRNA have been observed in adult SON neurons (Aguado et al., 1992; Zhou et al., 1999), and high expression of the IGF-1 receptor has been reported in the SON (Folli et al., 1994; Cardona-Gomez et al., 2000).

Using immunohistochemistry and in vivo and in vitro electrophysiological recordings, we show that IGF-1, which is highly present in this system, inhibits the activity of SON neurons through the simultaneous and complementary modulation of the two osmosensory systems, inhibiting mechanoreceptor channels and potentiating GlyR, revealing an acute and complex neuromodulatory role of IGF-1 in the adult brain.

\section{Materials and Methods}

All animal experiments were performed in accordance with the European Communities Council Directive of November 24, 1986 (86/609/ EEC) and follow the standards required by the governance of The Journal of Neuroscience. All measures were taken to minimize pain and discomfort of animals.

In vivo electrophysiological recordings. Extracellular recordings of SON OT and VP neurons from anesthetized (urethane intraperitoneally) adult male Wistar rats (250-400 g) were performed as described previously (Hussy et al., 1997). Rats placed in a stereotaxic apparatus were injected subcutaneously at all points of contention or surgery with $1 \%$ xylocaine (Astra Zeneca, Rueil Malmaison, France). Recording electrodes were pulled from borosilicate glass capillary and filled with a $0.5 \mathrm{M}$ sodium acetate solution (resistance, 10-20 M 2 ). They were brought down in the SON according to stereotaxic coordinates. A stimulation electrode was placed in the pituitary stalk allowing antidromic identification of SON neurons. Extracellular activity was acquired and analyzed using Spike2 software (Cambridge Electronic Design, Cambridge, UK). IGF-1 (500 ng/ml; human recombinant) was diluted in CSF-like medium as described previously (Hussy et al., 1997) and injected near the recorded neuron by the way a pressure pipette attached to the recording electrode, and connected to a picopump (World Precision Instruments, Stevenage, UK). VP neurons were identified by their typical phasic activity, and OT neurons were identified by their continuous firing and their activation by intravenous injection of cholecystokinin $(20 \mu \mathrm{g} / \mathrm{kg}$, i.v. $)$ (Leng et al., 1999). Electrical activity of OT neurons was characterized by calculating the mean basal frequency of discharge $F$ (in spikes/s) for each 5 min period. Analysis of the phasic activity of VP neurons included quantification of the following parameters: the firing frequency during active periods $(f)$, the mean duration of active periods (da) and silent periods (ds), and the activity quotient ( $Q$ ) (i.e., the proportion of time the neuron is active during a given time period) (da/total time). These were calculated per successive periods of 300 or $600 \mathrm{~s}$ for low and very active rhythmic cells, respectively, both before and from the beginning of drug application.

In vitro electrophysiological recordings of dissociated SON neurons. Dissociated neurons were obtained as described previously (Hussy et al., 1997). Young adult male Wistar rats (4 weeks of age) were decapitated without anesthesia, and their brain was rapidly removed and placed in an ice-cold oxygenated modified Locke solution (in mM: $140 \mathrm{NaCl}, 2.5 \mathrm{KCl}$, 10 HEPES, $1.2 \mathrm{KH}_{2} \mathrm{PO}_{4}$, 10 glucose, $2 \mathrm{CaCl}_{2}, 2 \mathrm{MgCl}_{2}$, pH 7.4; osmolarity, $300 \mathrm{mOsm} / \mathrm{L}$ ). SONs were taken out and incubated successively (25 min each) in DNase I $(0.5 \mathrm{mg} / \mathrm{ml})$ together with protease $\mathrm{X}$ and then protease XIV ( $1 \mathrm{mg} / \mathrm{ml}$ each) at room temperature. After thorough rinsing, SONs were mechanically dissociated through a pipette, and cell suspension was plated into tissue culture Petri dishes. SON neurons were selected based on their size (soma diameter, $\geq 12 \times 15 \mu \mathrm{m}$ ) (Oliet and Bourque, 1992; Hussy et al., 1997).

Recordings were realized using the perforated patch-clamp technique in either current- or voltage-clamp mode. Recording electrodes pulled from borosilicate glass capillary were filled with a solution containing the following (in mM): $150 \mathrm{KCl}, 10 \mathrm{HEPES}$, and $2.5 \mathrm{CaCl}_{2}$. Stock solution of amphotericin $\mathrm{B}(70 \mathrm{~mm})$ was prepared in DMSO and added to the pipette solution in the course of each experiment at a final concentration of 0.56 mM. A fresh solution was made every $1.5 \mathrm{~h}$, sonicated $10-15 \mathrm{~min}$, and kept in the dark. The electrode had resistance of 3-5 $\mathrm{M} \Omega$, and perforation was obtained within a few minutes after sealing onto the membrane. Currents and membrane potentials were amplified (List EPC7; Heka, Lambrecht, Germany), filtered (0.3-2 kHz, Bessel filter), and digitized (1-10 kHz) with pClamp6 (Axon Instruments, Union City, CA). Analyses were performed with pClamp9 and Origin software (Origin Lab, Northampton, MA). Series resistance was 15-30 $\mathrm{M} \Omega$ and was compensated to $50-60 \%$ for voltage-clamp recordings. To minimize voltage error when high concentrations of taurine were used, taurine dose-response curves were established with a different intrapipette solution (in mM: $125 \mathrm{KCH}_{3} \mathrm{SO}_{3}, 25 \mathrm{KCl}, 10$ HEPES, $2.5 \mathrm{CaCl}_{2}$, pH 7.2; osmolarity, $300 \mathrm{mOsm} / \mathrm{L}$ ), setting the $\mathrm{Cl}^{-}$equilibrium potential at $-40 \mathrm{mV}$. Holding potential was then adjusted to between -46 and $-66 \mathrm{mV}$ so that the maximal current amplitude did not exceed $1 \mathrm{nA}$. With this solution, a junction potential of $6 \mathrm{mV}$ was calculated at the tip of the electrode (Hussy et al., 1997), which was corrected. Neurons were constantly perfused with Locke medium through a gravity driven perfusion system placed in the vicinity of the recorded neurons. Stock solution of IGF-1 was prepared in $0.1 \mathrm{M} \mathrm{HCl}$ at a concentration of $0.5 \mathrm{mg} / \mathrm{ml}$, stored at $-80^{\circ} \mathrm{C}$, and diluted to final concentration in Locke medium. All pharmacological substances were added to the external medium, which contained $0.1 \%$ bovine serum albumin (BSA). Because of the $\mathrm{Gd}^{3+}$ chelating property of phosphates, $\mathrm{Gd}^{3+}$ was applied in a solution without $\mathrm{KH}_{2} \mathrm{PO}_{4}$, and the phosphate-containing Locke was shortly applied to accelerate the washout of $\mathrm{Gd}^{3+}$ (Le Guennec et al., 1996). Tyrphostin AG538 and AG825 were solubilized in DMSO at 10 and 100 mM. Final concentration of DMSO did not exceed $0.5 \%$, and this concentration had no effect on GlyR or its modulation by IGF-1. To construct dose-response curves for taurine, because our perfusion system did not permit application of all different taurine concentrations in the absence and presence of IGF-1 on each cell, we normalized each current amplitude to the amplitude of the current induced by a constant concentration of taurine $(300 \mu \mathrm{M})$ in the absence of IGF-1. Normalized amplitudes were fitted with Hill equation (Origin software) and finally expressed as a percentage of the evaluated maximum current in control condition. All statistical significance was assessed by paired Student's $t$ test. Unless otherwise specified, all chemicals were from Sigma (St. Quentin Fallavier, France).

Immunohistochemistry. Adult Wistar rats (200-400 g) were used, either untreated or treated with colchicine by an intracerebroventricular injection of colchicine $(10 \mu \mathrm{g} / 5 \mu \mathrm{l}$ into the lateral ventricle) $48 \mathrm{~h}$ before they were killed. After deep anesthesia with pentobarbital $(300 \mathrm{mg} / \mathrm{kg})$, rats were perfused through the ascending aorta with $100 \mathrm{ml}$ of PBS, $\mathrm{pH}$ 7.4, followed by $500 \mathrm{ml}$ of $4 \%$ paraformaldehyde (for confocal microscopy) or $4 \%$ paraformaldehyde plus $0.5 \%$ glutaraldehyde (for electron microscopy), in $0.1 \mathrm{~m}$ phosphate buffer, $\mathrm{pH}$ 7.4. The brain was removed and immersed in the same fixative for $8 \mathrm{~h}$. Tissues were cut with a vibratome into $40-\mu \mathrm{m}$-thick sections and rinsed in PBS. For confocal microscopy, sections were incubated for $48 \mathrm{~h}$ at $4^{\circ} \mathrm{C}$ with one or two primary antibodies, including mouse IgG monoclonal antibodies against IGF-1 (dilution, 1:1000; Upstate Biotechnology, Milton Keynes, UK) and VP or OT neurophysins (dilution, 1:500; kindly provided by Dr. D. Pow, University of Queensland, Brisbane, Australia) and rabbit IgG polyclonal antibodies against IGF-1 receptor $\beta$ (dilution, 1:500; Santa Cruz Biotechnology, Heidelberg, Germany), GFAP (dilution, 1:5000; Dako, Trappes, France), VP, and OT (produced by G.A.). The specificity of the commercial antibodies against IGF-1 and IGF-1 receptor is guaranteed by the manufacturers, and both provided convincing immunocytochemical data (Jiang et al., 1998; Hellawell et al., 2002). After rinsing in PBS, sections were incubated for $4 \mathrm{~h}$ with secondary antibodies against rabbit or mouse IgG (diluted, 1:2000) conjugated with cyanine 3 (Jackson ImmunoResearch, Soham, UK) or Alexa 488 (Molecular Probes, Eugene, OR). Primary and secondary antibodies were diluted in PBS containing 

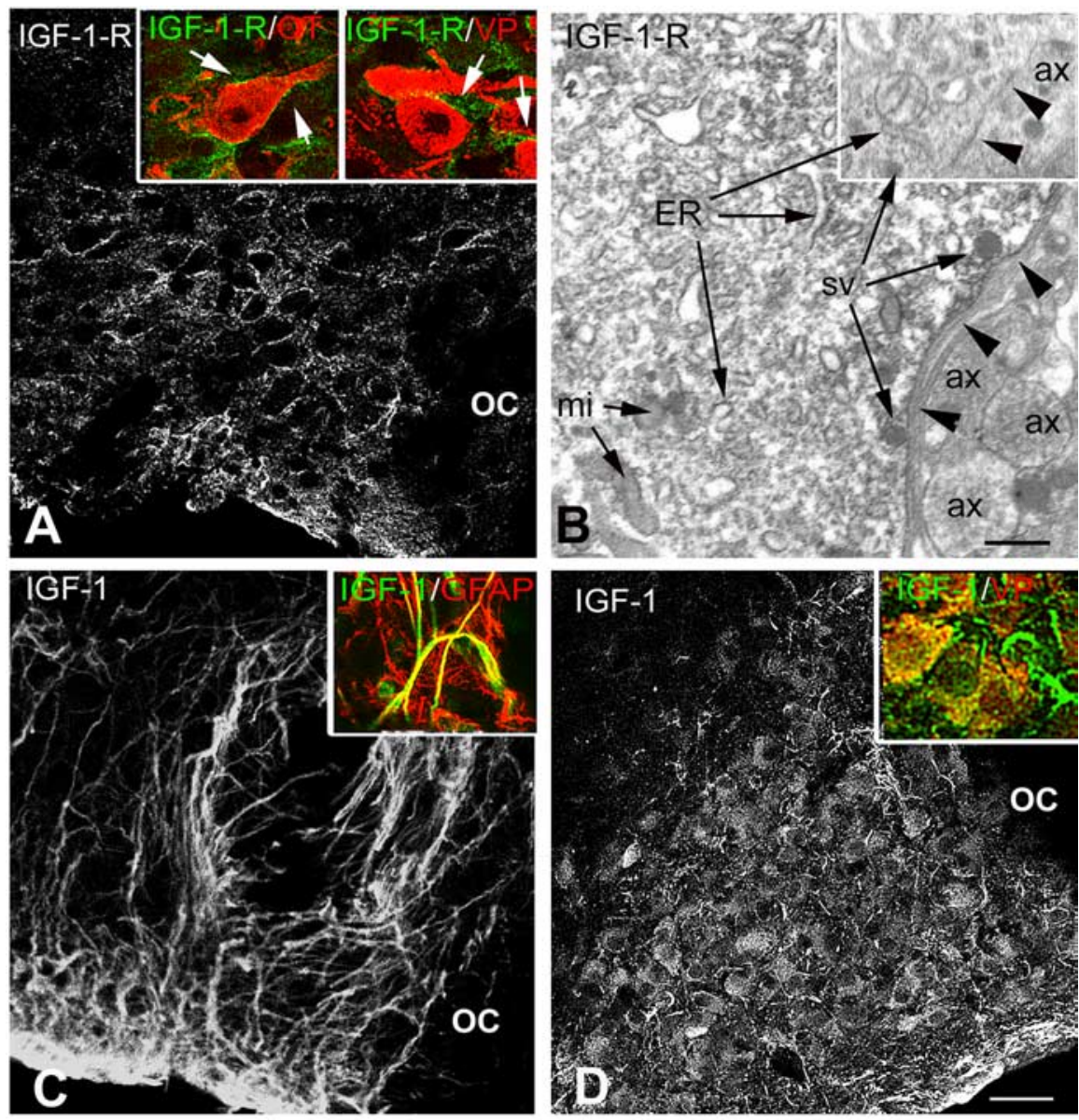

Figure 1. Immunocytochemical localization of IGF-1 receptor and IGF-1 within the SON. A, At the confocal microscopy level, immunostaining for IGF-1 receptor (IGF-1-R) is localized at the periphery of cell bodies dispersed throughout the SON. Insets, Double immunostaining for IGF-1-R and either OT or VP neurophysins showing that the receptor is localized at the periphery of both types of SON neurons (arrows). B, At the electron microscopy level, IGF-1-R immunostaining appears as electron-dense precipitates associated with both the endoplasmic reticulum and the limiting plasma membrane (arrowheads) of SON neuronal cell bodies, whereas surrounding structures are unlabeled. Inset, No immunostaining is found, regardless of whether associated with the endoplasmic reticulum (ER) or plasma membrane (arrowheads), in a control section processed in the absence of the primary antibody. C, Immunostaining for IGF-1 is associated with elongated astrocytic-like processes in a control untreated rat, where it colocalizes with GFAP (inset). $\boldsymbol{D}$, In a colchicine-treated rat, IGF-1 immunostaining is detected within most SON neurons and both VP-labeled neurons (inset, yellow) and VP-negative processes (inset, arrow). ax, Axon; mi, mitochondria; $O C$, optic chiasma; sv, secretory vesicle. Scale bars: $\boldsymbol{A}, \boldsymbol{C}, \boldsymbol{D}, 50 \mu \mathrm{m}$; insets, $20 \mu \mathrm{m} ; \boldsymbol{B}, 0.5 \mu \mathrm{m}$.

2\% BSA and $0.1 \%$ Triton X-100. After rinsing, sections were mounted in Mowiol (Calbiochem, La Jolla, CA) and observed under a Bio-Rad (Hercules, CA) MRC 1024 confocal laser-scanning microscope equipped with a krypton/argon-mixed gas laser. The background noise of each confocal image was reduced by averaging five image inputs. Immunostained structures were studied on single confocal images of 1-2 $\mu \mathrm{m}$ thick. For electron microscopy, sections were incubated for $48 \mathrm{~h}$ at $4^{\circ} \mathrm{C}$ with the IGF-1 receptor antibody (dilution, 1:1000) in PBS containing $0.1 \%$ saponin, rinsed in PBS, and incubated for $12 \mathrm{~h}$ at $4^{\circ} \mathrm{C}$ with a peroxidaselabeled Fab fragment of goat $\operatorname{IgG}$ anti-rabbit $\operatorname{IgG}$ and with $0.1 \% 3,3^{\prime}$ diaminobenzidine diluted in $0.05 \mathrm{M}$ Tris buffer, $\mathrm{pH} 7.3$, in the presence of $0.2 \% \mathrm{H}_{2} \mathrm{O}_{2}$. Immunostained sections were rinsed in $0.1 \mathrm{M}$ cacodylate buffer, $\mathrm{pH} 7.3$, postfixed in $1 \%$ osmium tetroxide in the same buffer, dehydrated in graded concentrations of ethanol, and embedded in Araldite. Punches of $1.5 \mathrm{~mm}$ in diameter were cut through the supraoptic nucleus, mounted on Araldite blocks, and cut into ultrathin sections, which were observed in a Hitachi (Tokyo, Japan) 7100 electron microscope after slight uranyl acetate counterstaining. Unaltered digitized images were transferred to a computer, and Adobe Photoshop (Adobe Systems, San Jose, CA) was used to prepare final figures. For all immunostaining experiments, no labeling was detected when applying secondary antibodies in the absence of previous application of primary antibodies.

Measurement of taurine release. Release of taurine from SON isolated from adult male Wistar rats (150-200 g) was measured as described previously (Deleuze et al., 1998, 2000). Rats were decapitated without anesthesia, and their brains were rapidly removed and placed in an oxygenated external solution (in mM: 130 $\mathrm{NaCl}, 5 \mathrm{KCl}, 2 \mathrm{CaCl}_{2}, 2 \mathrm{MgCl}_{2}, 1.2 \mathrm{KH}_{2} \mathrm{PO}_{4}, 10$ HEPES, 10 glucose, 20 sucrose, $\mathrm{pH}$ 7.4; osmolarity, $300 \mathrm{mOsm} / \mathrm{L}$ ) at $4^{\circ} \mathrm{C}$. SONs were carefully dissected and freed from any residual optic tracts and blood vessels and were incubated for $40 \mathrm{~min}$ in oxygenated external solution supplemented with $500 \mathrm{~nm}\left[{ }^{3} \mathrm{H}\right]$ taurine (Amersham Biosciences, Orsay, France) at $35^{\circ} \mathrm{C}$, washed three times, and placed in perfusion chambers. Chambers were perfused with oxygenated solution at $35^{\circ} \mathrm{C}$ at a rate of $250 \mu \mathrm{l} / \mathrm{min}$. The perfusate during the first $20 \mathrm{~min}$ was wasted, samples were then collected every 2 min using a sample collector (Gilson, Roissy, France), and radioactivity in each sample was estimated by scintillation counting. Basal release of taurine was fitted with single exponential function, and data points were divided by the fit to express release relative to basal. Hypoosmotic solution was obtained by removing sucrose to obtain a solution of $280 \mathrm{mOsm} / \mathrm{L}$. Analysis and fits were performed with Origin software.

\section{Results}

Immunolocalization of IGF-1 and its receptor in the SON

The SON exhibited moderate to intense immunostaining for either IGF-1 or IGF-1 receptor, with very faint labeling in the surrounding regions. Immunostaining for IGF-1 receptor was detected at the periphery of most neuronal cell bodies within the SON (Fig. 1A). Double immunostaining indicated that labeling was associated with both VP and OT neurons. At the electron microscopy level, staining clearly appeared within the neurons and in their plasma membrane, with little or no labeling in other cell types (Fig. $1 \mathrm{~B}$ ). In control rats, intense IGF-1 immunostaining was associated with elongated, astrocytic-like processes extending throughout the nucleus, whereas very faint immunostaining was seen in neurons (Fig. 1C). In colchicinetreated rats, IGF-1 immunostaining was detected within most SON neurons, whereas it appeared markedly decreased within astrocytic processes (Fig. 1D). The examination of doubleimmunostained sections confirmed that IGF-1 immunostaining was associated with both GFAP-labeled astrocytic processes and VP- or OT-labeled neurons.

\section{In vivo effects of IGF-1 on the activity of SON neurons}

Basal activity of SON neurons was recorded 15-20 min before a $30-600 \mathrm{~s}$ application of IGF-1 (500 ng/ml). IGF-1 inhibited the phasic activity of VP neurons $(n=8)$ (Fig. $2 A)$ by decreasing the duration of active periods by $40 \pm 9 \%$ and increasing the duration of silences by $257 \pm 99 \%$. This results in a significant $54 \pm$ 


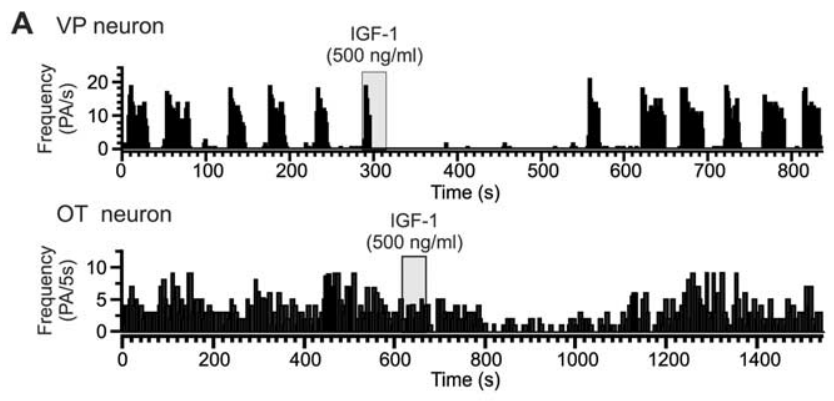

B
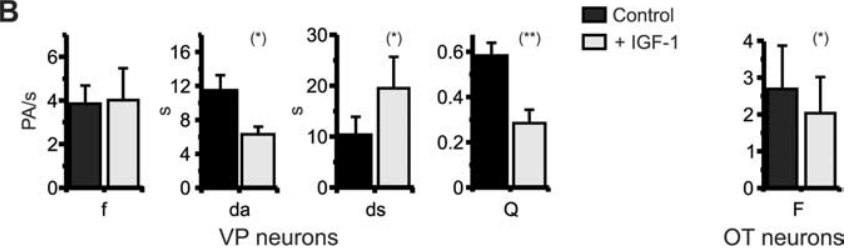

OT neurons

Figure 2. IGF-1 inhibits the in vivo electrical activities of VP and OT neurons. A, Pressure ejection of IGF-1 in the vicinity of SON neurons reversibly inhibited the phasic activity of VP neurons (top) and the continuous activity of OT neurons (bottom). In vivo extracellular recordings from an anesthetized rat are shown. $\boldsymbol{B}$, Histograms summarizing the effect of IGF-1 on VP (left) and OT (right) neuron activity. For VP neurons ( $n=8)$, IGF-1 significantly decreased the mean duration of active periods (da) and increased the mean duration of silent periods (ds), resulting in a strong decrease in activity quotient (Q). IGF-1 did not affect mean intraburst frequency $(f)$. For OT neurons ( $n=7)$, IGF-1 significantly decreased the mean frequency of firing $(F) .{ }^{*} p<0.05 ;{ }^{* *} p<0.0002$.

$8 \%$ decrease of the activity quotient $Q$ (Fig. $2 B$ ). The firing frequency within each burst of activity was not affected by the growth factor. OT neurons were also inhibited by IGF-1, with a significant $32 \pm 7 \%$ decrease of the firing frequency $(n=7)$ (Fig. 2 ). The effects of IGF-1 were fully reversible within a few minutes after the end of IGF-1 injection and could be repeated several times on a single cell (data not shown).

\section{In vitro effects of IGF-1 on acutely isolated SON neurons}

The effect of IGF-1 (50 ng/ml) was first studied on dissociated SON neurons in whole-cell configuration, but IGF-1 induced a hyperpolarization in only 4 of 31 neurons (data not shown). Recordings were therefore performed in the perforated-patch configuration to preserve intracellular integrity. In these conditions, all SON neurons recorded under current clamp $(n=101)$ responded to IGF-1 by a hyperpolarization associated with a reduction in electrical activity (Fig. $3 A$ ). The effect of IGF-1 was rapid (onset of 1.5-3.5 s) and totally reversible within a few seconds. It did not depend on neuronal activity, because it was still present after inhibition of spontaneous activity by injection of a hyperpolarizing current. The hyperpolarization actually was larger at more negative potentials $(-5.0 \pm 0.3 \mathrm{mV}$ at $-55 \mathrm{mV}, n=49$; $-7.6 \pm 0.2$ at $-70 \mathrm{mV}, n=79)$. IGF-1 did not affect the time course of single action potentials (data not shown), suggesting the lack of effect on voltage-dependent currents. IGF-1-induced hyperpolarization was associated with a small outward current under voltage clamp $(+5.8 \pm 0.3 \mathrm{pA}$ at $-70 \mathrm{mV} ; n=15)$ (Fig. $3 B)$. Given the high resistance of these neurons $(1.19 \pm 0.02 \mathrm{G} \Omega$; $n=156$ ), such a small current is sufficient to account for the observed hyperpolarization.

The amplitude of the hyperpolarization depended on the concentration of IGF-1. An effect was already observed at $1 \mathrm{ng} / \mathrm{ml}$
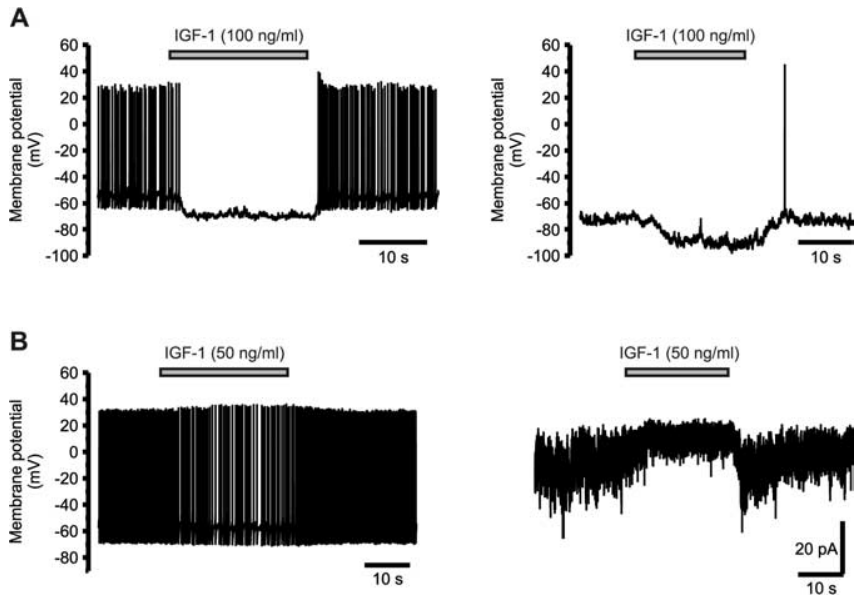

Figure 3. IGF-1 inhibits the activity of SON neurons in vitro by activating an outward current. $\boldsymbol{A}$, Application of IGF-1 induced a rapid hyperpolarization associated with a decrease or cessation of firing of all isolated SON neurons (left). The hyperpolarizing effect of IGF-1 was independent of electrical activity, because it was still observed after injection of a constant negative current that lowered the membrane potential and shut down spontaneous activity (right). Current-clamp recordings of an acutely isolated neuron are shown. $\boldsymbol{B}$, The hyperpolarization induced by IGF-1 under current clamp (left) is associated in the same neuron with a small outward current under voltage clamp (holding potential, $-70 \mathrm{mV}$ ), accompanied by a decrease in noise amplitude (right).

$(0.13 \mathrm{nM})$, and increasing doses (up to $100 \mathrm{ng} / \mathrm{ml}$ or $13 \mathrm{~nm}$ ) induced responses of proportionally larger amplitude (Fig. 4A). Qualitatively similar results were obtained under voltage clamp. Implication of the IGF-1 receptor was checked using tyrphostin AG538, a tyrosine kinase inhibitor known to block autophosphorylation of IGF-1 receptor with high affinity (Blum et al., 2000). A 2 min preapplication of $1 \mu \mathrm{M}$ tyrphostin AG538 had no effect on membrane potential but completely blocked the hyperpolarization induced by IGF-1 $(n=9)$ (Fig. $4 B)$. This effect was reversible within a few minutes. As a control for the specificity of tyrphostin AG538 on IGF-1 receptor, we tested the action of tyrphostin AG825, another tyrosine kinase inhibitor that has no effect on this receptor (Parrizas et al., 1997). Preapplication of 50 $\mu \mathrm{M}$ tyrphostin AG825 did not prevent IGF-1-induced hyperpolarization $(n=9)$ (Fig. $4 B)$. To test for second messengers implied in the effect of IGF-1, we used the PI3 kinase inhibitor wortmannin. The hyperpolarization induced by IGF-1 was essentially and reversibly suppressed by a $1 \mathrm{~min}$ preapplication of 50 nM wortmannin (90.5 $\pm 0.5 \%$ inhibition; $n=13$ ) (Fig. $4 C$ ). Wortmannin had little effect by itself on cell membrane potential.

IGF-1 inhibits stretch-inactivated mechanoreceptor current Under voltage clamp, IGF-1 induced an outward current associated with a manifest reduction in the variance of the current (Fig. $3 B$ ), suggesting a reduction in channel activity. We thus applied voltage ramps from -90 to $-60 \mathrm{mV}$, a window devoid of voltageactivated current. The outward current induced by IGF-1 was associated with a reduced slope of the current-voltage relationship, confirming the inhibition of a resting conductance (Fig. $5 A$ ). Intersection of linear fits of the current curves gave a reversal potential of $-36.3 \pm 0.5 \mathrm{mV}(n=12)$. This value did not correspond to the equilibrium potential of anions $\left(E_{\mathrm{Cl}}\right.$ is $\sim 0 \mathrm{mV}$ in our recording conditions) or of any specific cation species present in our recording solutions, which suggested the involvement of a nonselective cation conductance. In fact, this value is very close to that reported for the $\mathrm{Gd}^{3+}$-sensitive stretch-inactivated cation 
A
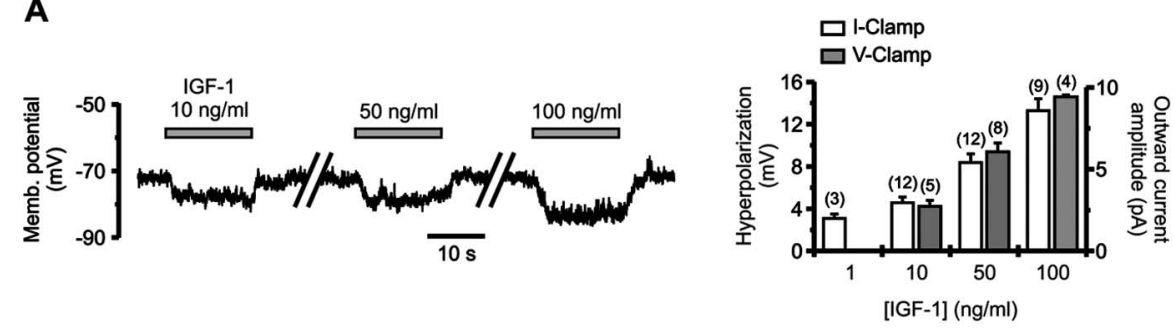

B
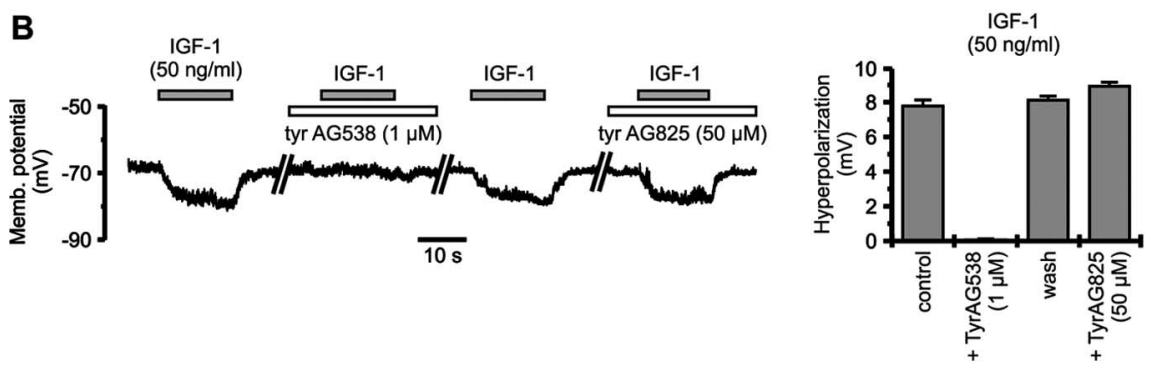

C

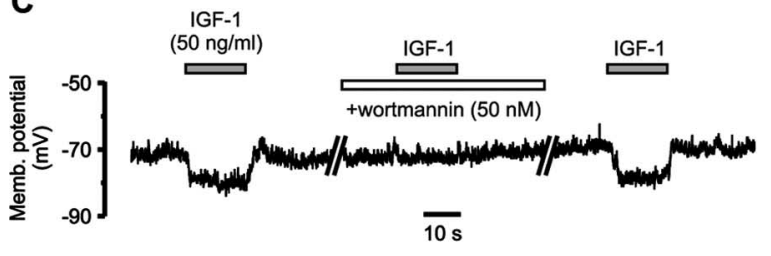

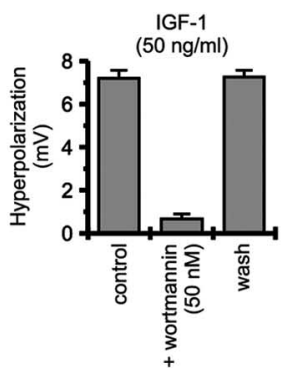

Figure 4. Hyperpolarizing effect of IGF-1 implies the IGF-1 receptor and activation of PI3 kinase. $\boldsymbol{A}$, The amplitude of IGF-1induced hyperpolarization of isolated SON neurons increased with the concentration of the growth factor (current-clamp recordings; left). Right, Histograms showing the dose dependency of the hyperpolarization (current clamp; membrane potential, approximately $-70 \mathrm{mV}$; left axis) and outward current (voltage clamp; holding potential, $-70 \mathrm{mV}$; right axis) induced by IGF-1. Numbers of observations are indicated above columns. $\boldsymbol{B}$, Two minute preapplication of the IGF-1 receptor inhibitor tyrphostin AG538 (1 $\mu \mathrm{M})$ completely suppressed the hyperpolarizing effect of IGF-1, without affecting the membrane potential by itself. Blockade was reversible within 3-5 min. In contrast, tyrphostin AG825, which does not affect the IGF-1 receptor, had no effect even at 50 times higher concentration on the hyperpolarization induced by IGF-1. C, One minute preapplication of the PI3 kinase inhibitor wortmannin almost completely blocked the hyperpolarization induced by IGF-1. Inhibition was fully reversible within 3-5 min. Recordings under current clamp are shown.

channels present in these cells and known to be active at rest under isoosmotic condition (Oliet and Bourque, 1994; Bourque, 1998). Application of $100 \mu \mathrm{M} \mathrm{Gd}^{3+}$ induced a hyperpolarization of $-10.6 \pm 0.5 \mathrm{mV}$ (at $-70 \mathrm{mV} ; n=12$ ) (Fig. $5 B$ ), indicative of the inhibition of the mechanosensitive current, and almost completely blocked the hyperpolarization induced by IGF-1. Blockade of the effect of IGF-1 was not a result of the hyperpolarizing action of $\mathrm{Gd}^{3+}$, because IGF-1-induced hyperpolarization was larger at more negative membrane potential and because the effect of IGF-1 was still blocked even after manually resetting the membrane potential close to its original value $(n=7$; data not shown). Blockade of IGF-1 response by $\mathrm{Gd}^{3+}$ reached $97.7 \pm$ $0.3 \%(n=12)$ and was fully reversible.

If IGF-1 acts on mechanoreceptor channels, its effect should depend on the osmolarity of the external medium. Application of a hypertonic solution ( $5 \%$ increase in osmolarity) depolarized the neurons by $+4.7 \pm 0.4 \mathrm{mV}$ (from $-70 \mathrm{mV} ; n=10$ ) (Fig. $5 C$ ) as a result of an increased probability of opening of mechanoreceptor channels (Oliet and Bourque, 1994; Bourque, 1998). In these conditions, hyperpolarization induced by IGF-1 was increased by $50 \pm 1 \%(n=10)$ in a reversible manner. Enhance- ment of the effect of IGF-1 was not attributable to the potential change induced by the hyperosmotic medium, because even after the membrane potential was manually reset to the original level, the hyperpolarization elicited by IGF-1 was still increased to a similar extent $(n=7)$ (Fig. $5 C)$. Application of a hypotonic solution ( $8 \%$ decreased in osmolarity) led to a strong hyperpolarization $(-15.7 \pm 1.3$ $\mathrm{mV}$ at $70 \mathrm{mV} ; n=5$ ) (Fig. $5 C$ ), resulting from closing of all mechanoreceptors (Oliet and Bourque, 1994; Bourque, 1998), and IGF-1 had no more effect (97 \pm $1 \%$ inhibition; $n=5$ ). This effect was fully reversible. Again, this effect was independent of the membrane potential change evoked by the hypotonic stimulus, because IGF-1-induced hyperpolarization was still blocked after resetting the membrane potential to prestimulus level $(n=3$; data not shown). Therefore, effect of IGF-1 depends on osmotic pressure and follows the level of activation of mechanoreceptors.

\section{IGF-1 potentiates taurine-activated glycine receptor current}

We then checked whether IGF-1 could also act on the other osmosensitive component of these neurons, the GlyR. In current-clamp mode, under hypoosmotic condition to shut down all mechanoreceptor channels, application of a low concentration of the GlyR agonist taurine (100 $\mu \mathrm{M})$ induced a depolarization associated with resuming of firing (Fig. 6A). This depolarizing effect of the activation of the Gly $\mathrm{Cl}^{-}$current is expected in our recording conditions, with a $\mathrm{Cl}^{-}$equilibrium potential of $\sim 0 \mathrm{mV}$. Application of IGF- 1 in addition to taurine further depolarized the neuron and increased the firing frequency $(n=3)$. In these conditions, IGF-1 had no effect in the absence of taurine (Fig. $5 C$ ). Under voltage clamp, taurine (100 $\mu \mathrm{M})$ induced a small and sustained current, corresponding to the activation of GlyR as reported previously (Hussy et al., 1997). Coapplication of taurine and IGF-1 strongly increased the amplitude of taurine-activated current in a reversible manner (Fig. $6 \mathrm{~B})$. The magnitude of the increase was variable from cell to cell, ranging from 44 to $560 \%$, with a mean value of $260 \pm 24 \%(n=$ 47). Coapplication with IGF-1 also often accelerated the activation kinetics and revealed a desensitizing component. The effect of IGF-1 was clearly on the GlyR, because strychnine ( $1 \mu \mathrm{M})$ completely blocked the current $(n=11)$, and IGF- 1 alone had no effect. The action of IGF- 1 was rapid, taking place within $1 \mathrm{~s}$, and was not enhanced by preapplication of IGF-1 (Fig. $6 B$ ).

To verify the implication of the IGF-1 receptor, we applied various concentrations of the growth factor and found that the potentiating effect of IGF-1 on GlyR was dose dependent in the same range of concentrations as the inhibition of mechanoreceptors $(1-100 \mathrm{ng} / \mathrm{ml} ; n=6)$ (Fig. $7 A)$. A significant potentiation was already observed at $1 \mathrm{ng} / \mathrm{ml}(p<0.05 ; n=6)$. Moreover, preapplication of tyrphostin AG538 $(1 \mu \mathrm{M})$, the tyrosine kinase 
inhibitor that blocks the IGF-1 receptor, did not affect the amplitude or kinetics of taurine-activated current but reversibly abolished its potentiation by IGF-1 $(n=9)$ (Fig. 7B), whereas tyrphostin AG825 (50 $\mu \mathrm{M})$, which is inactive on the IGF-1 receptor, had no effect $(n=6)$ (Fig. $7 C)$. However, in contrast to the effect on mechanoreceptors, preapplication of $50 \mathrm{nM}$ wortmannin did not affect taurine-activated current or prevent its potentiation by IGF-1, ruling out the implication of PI3 kinase ( $n=$ 6) (Fig. 7D).

Acceleration of kinetics and increase in desensitization could reflect a shift in the apparent affinity of the receptor for the agonist. We checked this by comparing dose-response curves for taurine in the absence and presence of IGF-1. To prevent activation of $\mathrm{GABA}_{\mathrm{A}}$ receptor by high concentrations of taurine, $3 \mu \mathrm{M} \mathrm{GABA}$ receptor antagonist gabazine was added to all external media (Hussy et al., 1997). Potentiation by IGF-1 depended on the concentration of taurine, becoming smaller with increasing doses (Fig. $8 \mathrm{~A}$ ). Dose-response curves indicated that IGF-1 did not change the maximal current activated by taurine, which in the presence of IGF-1 reached $107 \pm 4 \%$ of that in control condition but shifted the curve to the left changing the $\mathrm{EC}_{50}$ value from $476 \pm 61$ to $288 \pm 32 \mu \mathrm{M}$ (Fig. $8 B$ ).

\section{IGF-1 does not affect taurine release from SON astrocytes}

Because release of taurine from SON astrocytes is enhanced by tyrosine phosphorylation (Deleuze et al., 2000), we tested whether IGF-1 could also modulate taurine release from acutely isolated SON, which was previously shown to occur almost exclusively from astrocytes (Deleuze et al., 1998). However, application of IGF-1 $(50 \mathrm{ng} / \mathrm{ml})$ had no effect on basal release of taurine and did not affect the increase in release induced by a mild hypotonic stimulus $(-20 \mathrm{mOsm} / \mathrm{L})$, with a peak reaching $182 \pm 14 \%$ of basal release in control condition $(n=3)$ and $181 \pm 8 \%$ in the presence of IGF-1 $(n=4)$ (Fig. 9). This result is in agreement with the apparent absence of labeling of the IGF-1 receptor in non-neuronal cells in the SON.

\section{Discussion}

We demonstrated that IGF-1 is an inhibitory regulator of SON neuron activity in the adult rat both in vivo and in vitro via the complementary modulation of the two osmosensitive components of SON neurons, which involves two different intracellular pathways. By both shutting down the excitatory cationic mechanoreceptor current and enhancing the inhibitory ${\mathrm{GlyR} \mathrm{Cl}^{-}}^{-}$current, IGF-1 appears as a potent inhibitory modulator.

B

D effect of IGF-1.
A
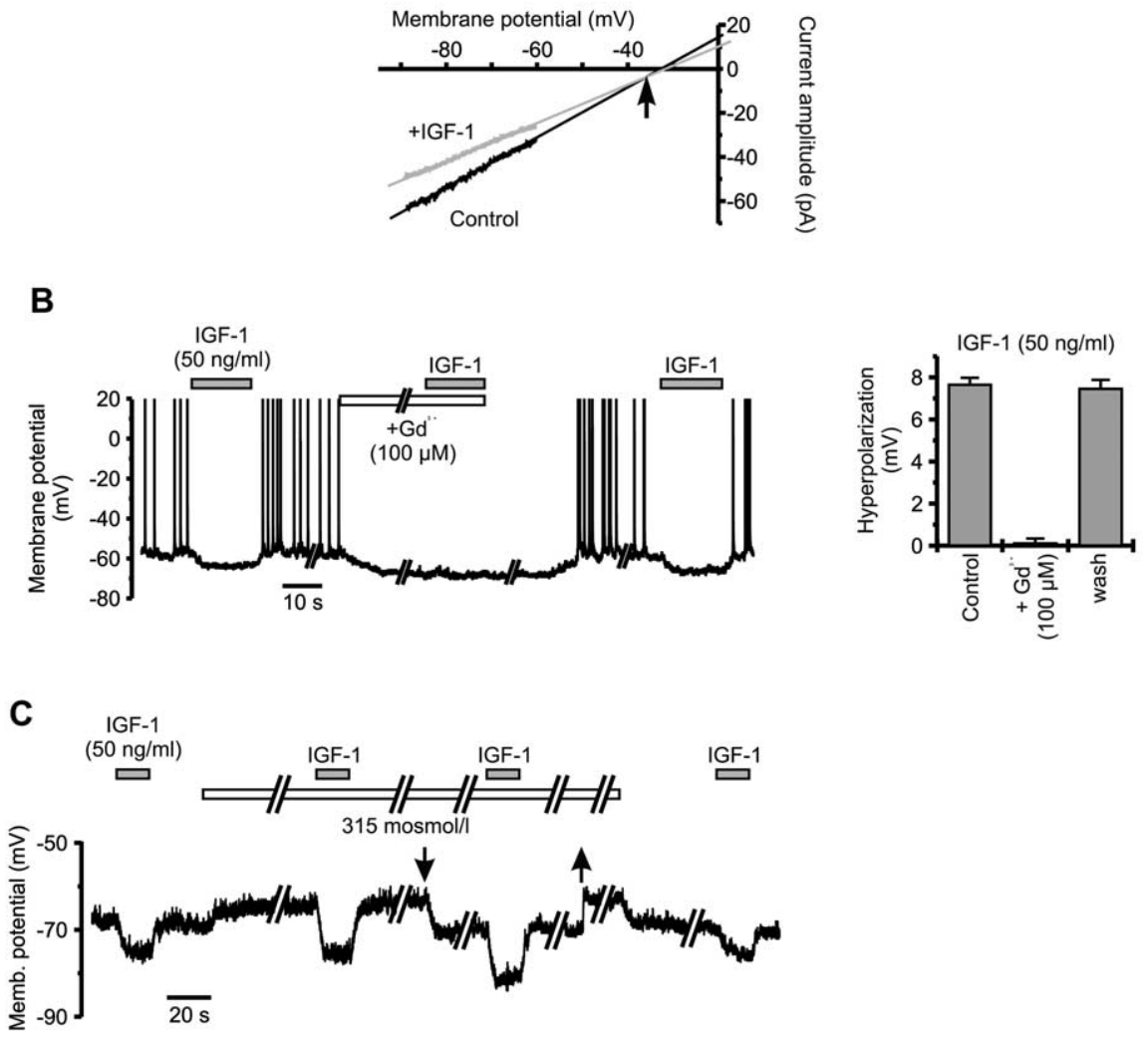

E

IGF-1 $(50 \mathrm{ng} / \mathrm{ml})$
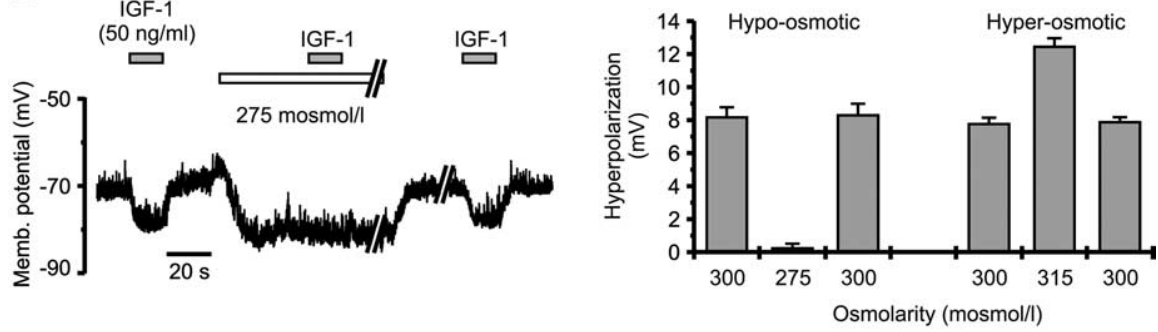

Figure 5. IGF-1 hyperpolarizes isolated SON neurons by inhibiting the mechanoreceptor current. $\boldsymbol{A}$, Slow ( $23 \mathrm{mV} / \mathrm{s})$ voltage ramps from -90 to $-60 \mathrm{mV}$ were applied onto a neuron under voltage clamp in control condition and in the presence of $50 \mathrm{ng} / \mathrm{ml}$ IGF-1. The currents from 24 successive ramps were averaged and fitted with linear regressions. The outward current induced by IGF-1 is associated with a decrease in the slope conductance, indicating the inhibition of a current active at rest. The reversal potential of this current (intersection of linear regression lines; arrow) was $-36.0 \mathrm{mV}$. B, Application of $\mathrm{Gd}^{3+}$ induced a hyperpolarization of the neuron and completely and reversibly blocked the hyperpolarizing effect of IGF-1. Recording under current clamp is shown. $\boldsymbol{C}-\boldsymbol{E}$, Sensitivity of the hyperpolarizing effect of IGF-1 to the osmolarity of external medium. $\boldsymbol{C}$, Application of a hyperosmotic medium (from 300 to $315 \mathrm{m0sm} / \mathrm{L}$ by adding $7.5 \mathrm{~mm} \mathrm{NaCl}$ ) induced a depolarization (activation of the mechanoreceptor current) and increased the amplitude of the hyperpolarization in response to IGF-1. Increased magnitude of the effect of IGF-1 effect is still present when the membrane potential is reset manually close to its original value (arrows). D, Application of a hypoosmotic medium (from 300 to $275 \mathrm{m0sm} / \mathrm{L}$ by removal of $12.5 \mathrm{~mm} \mathrm{NaCl}$ ) induced a hyperpolarization (inhibition of the mechanoreceptor current) and blocked the hyperpolarizing effect of IGF-1. $\boldsymbol{E}$, Histogram summarizing the osmosensitivity of the

IGF-1 has been shown to regulate various ion channels and ionotropic receptors in neurons (Blair and Marshall, 1997; Wang and Linden, 2000; Gonzalez de la Vega et al., 2001; Savchenko et al., 2001; Nunez et al., 2003), although most of these studies were realized on immature neurons. Interestingly, the related insulin and leptin also modulate several ion channels (Fadool et al., 2000; Spanswick et al., 2000; Shanley et al., 2002), as do other neurotrophins (Kafitz et al., 1999; Levine and Kolb, 2000; Tucker and Fadool, 2002). Leptin notably inhibits the activity of SON neurons in brain slices by an unknown mechanism (Honda et al., 
A
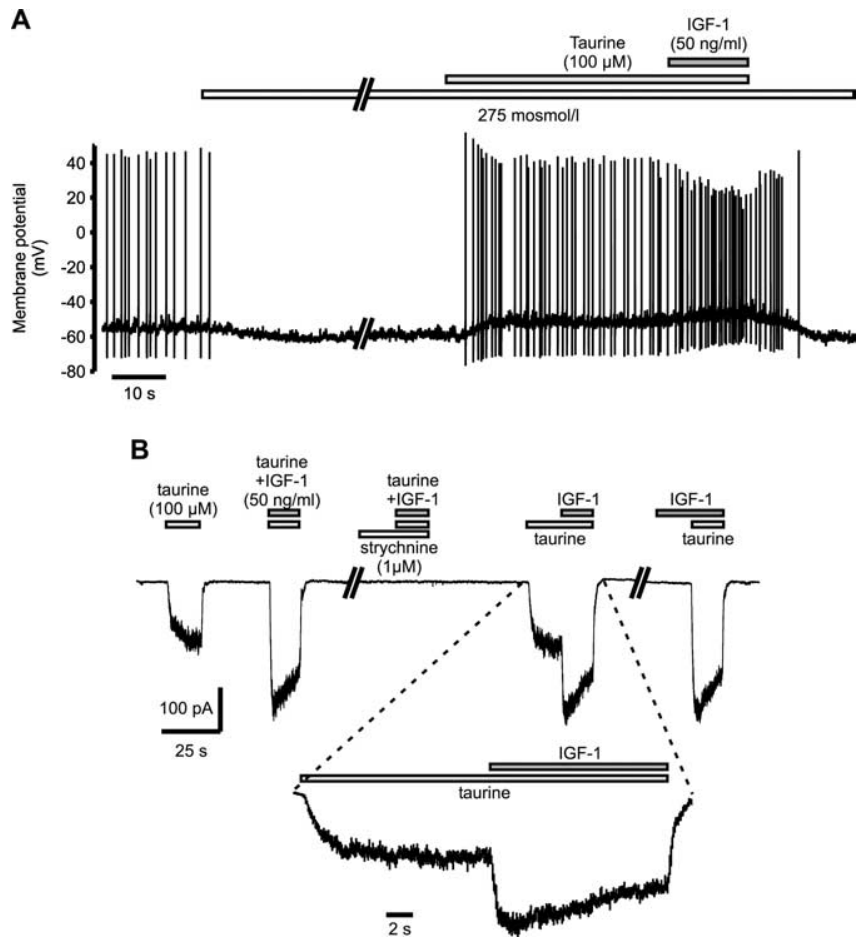

Figure 6. IGF-1 potentiates taurine-activated GlyR current in isolated SON neurons. $\boldsymbol{A}$, The effect of IGF-1 on GlyR was tested under current clamp after hypoosmotic blockade of all mechanoreceptor current. In our recording conditions ( $\mathrm{Cl}^{-}$equilibrium potential of $\left.\sim 0 \mathrm{mV}\right)$, application of $100 \mu$ m taurine induced a depolarization, which was reversibly increased by IGF-1. $\boldsymbol{B}$, The amplitude of taurine-activated current under voltage clamp was enhanced by coapplication with $50 \mathrm{ng} / \mathrm{ml}$ IGF-1. IGF-1 also fastened the kinetics of activation and revealed a desensitizing component. The increased current was completely suppressed by a 1 min preapplication of strychnine $(1 \mu \mathrm{M})$. The effect of IGF-1 was very rapid $(<1 \mathrm{~s})$ and did not require preapplication. Holding potential was $-66 \mathrm{mV}$.

2002). This suggests that these proteins may act as acute modulators of synaptic and electrical neuronal activities (Lu, 2003). Our present findings further support a possible major neuromodulatory role of IGF-1 in the adult mammalian nervous system.

\section{Both IGF-1 receptor and IGF-1 are present within the SON of adult rats}

A maintained expression of IGF-1 receptors in adult rat SON neurons has been reported previously (Folli et al., 1994; CardonaGomez et al., 2000). We confirmed this and further showed that this receptor is present on the soma and dendrites of both OT and VP neurons, providing morphological support to our functional results. IGF-1 immunoreactivity was detected within both neurons and astrocytes. As reported previously (Zhou et al., 1999), IGF-1 immunostaining of SON neurons was only detected after colchicine-induced blockade of intracellular trafficking, which indicates a low rate of expression of the peptide. Under basal conditions, intense IGF-1 immunoreactivity was associated with numerous astrocytic processes that run between neurons throughout the SON. The origin of this astrocytic IGF-1 is unclear, because IGF-1 mRNA has not been detected in SON astrocytes (Zhou et al., 1999). Astrocytes could specifically accumulate circulating IGF-1, as do tanycytes, specialized astrocytes from ventromedial hypothalamus (Fernandez-Galaz et al., 1996). The decreased astrocytic IGF-1 immunostaining by colchicine treatment could then result from decreased membrane expression of a transporter protein in the glial cell or decreased intracellular traf-
A
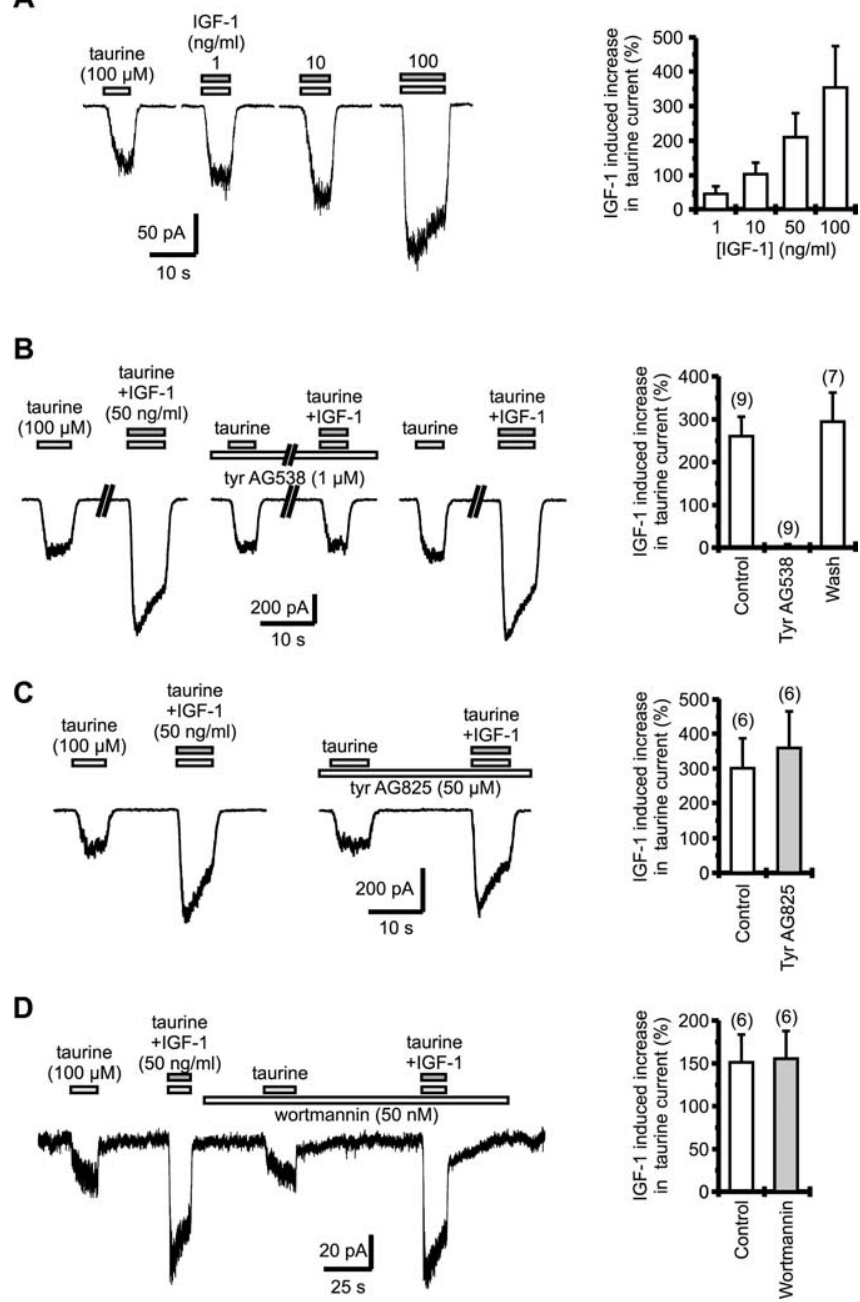

Figure 7. Potentiation of GlyR by IGF-1 requires activation of IGF- 1 receptor. $A$, Potentiation of taurine-activated current was dose dependent, with a significant effect already at $1 \mathrm{ng} / \mathrm{ml}$. Voltage-clamp recording of an isolated SON neuron was at a holding potential of $-50 \mathrm{mV}$. Right, Average dose-response histogram $(n=6)$. B. Two minute preapplication of the IGF-1 receptor inhibitor tyrphostin AG538 (1 $\mu \mathrm{M})$ did not affect the amplitude of taurine-induced current but completely suppressed the potentiating effect of IGF-1. Blockade was reversible within $5 \mathrm{~min}$. The voltage-clamp recording was at a holding potential of $-66 \mathrm{mV}$. C, Tyrphostin AG825 $(50 \mu \mathrm{M})$, which is inactive on the IGF-1 receptor, had no effect on potentiation of GlyR current by IGF-1. The voltage-clamp recording was at a holding potential of $-66 \mathrm{mV}$. D, Application of wortmannin had no effect on either taurine-induced current or its potentiation by IGF-1. Voltage-clamp recording was at a holding potential of $-46 \mathrm{mV}$. Numbers of observations are indicated above histograms.

ficking of IGF-1. It will be important to determine the precise cellular origin of IGF-1 acting on neuronal receptors in the SON and the physiological regulation of its release.

\section{IGF-1 inhibits in vivo activity of SON neurons}

We demonstrated that application of IGF-1 in the SON in vivo inhibits the activity of SON neurons. Interestingly, VP neurons were more affected than OT neurons. If both neuron populations express mechanoreceptors and GlyR (Hussy et al., 1997; Bourque, 1998), we reported previously that the in vivo endogenous inhibitory influence of GlyR activity was weaker on OT than on VP neurons (Hussy et al., 1997), possibly because of a lower amount of taurine released around OT neurons. The lower level of GlyR basal activation could possibly account for the weaker 
A

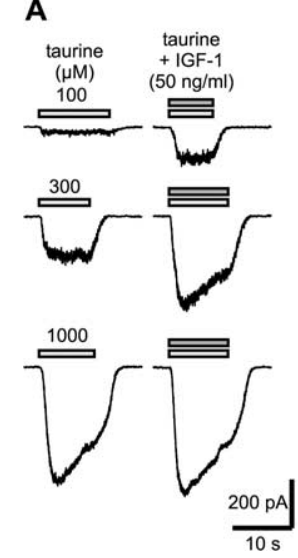

B

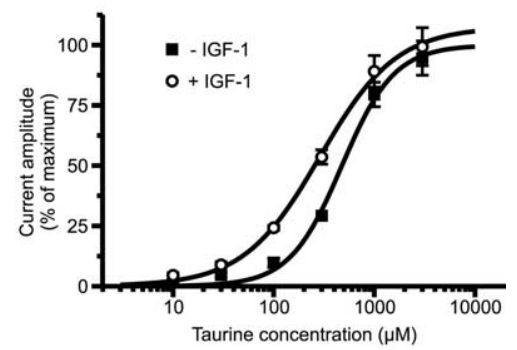

Figure 8. IGF-1 potentiates GlyR current by increasing the agonist apparent affinity. $A$, Effect of IGF-1 $(50 \mathrm{ng} / \mathrm{ml})$ on the currents evoked by three increasing concentrations of taurine, at a holding potential of $-46 \mathrm{mV}$. The magnitude of the potentiation depended on the agonist concentration, and IGF- 1 had little effect at near-saturating doses of taurine. Recordings were performed in the presence of $3 \mu \mathrm{m}$ gabazine to prevent activation of $\mathrm{GABA}_{A}$ receptors by high concentrations of taurine. $\boldsymbol{B}$, Dose-response curves for taurine in the absence and presence of IGF-1. All current amplitudes were normalized to the maximal amplitude estimated in the absence of IGF-1. IGF-1 shifts the curve to the left with no change in the maximal amplitude. Each point is the average obtained from 5 to 11 cells.

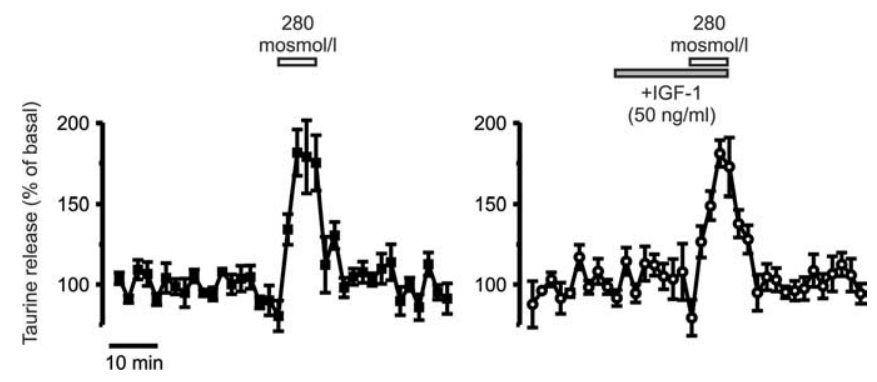

Figure 9. IGF-1 does not modulate taurine release from SON astrocytes. Application of IGF-1 did not affect basal $\left[{ }^{3} \mathrm{H}\right]$ taurine release measured from isolated whole SON or stimulated release by a mild hypotonic stimulus ( $n=3$ and 4 in the absence and presence of IGF-1, respectively).

inhibitory effect of IGF-1. Alternatively, this difference may also result from a nonuniform influence of endogenous IGF-1 or from a differential regulation linked to the different signaling pathways involved in the effects of IGF-1.

\section{Inhibition of mechanoreceptors by IGF-1}

IGF-1 hyperpolarized dissociated SON neurons through the inhibition of a cation current active at rest. Its reversal potential and sensitivity to $\mathrm{Gd}^{3+}$ and to extracellular osmotic pressure are identical to those of stretch-inactivated cation channels that carry the intrinsic osmosensitivity of SON neurons (Bourque, 1998; Voisin and Bourque, 2002). IGF-1 thus modulates the electrical activity of SON neurons via inhibition of the mechanosensitive channels. The very high sensitivity of the effect to IGF-1, blockade by the tyrphostin AG538, a tyrosine kinase inhibitor known to block IGF-1 receptor autophosphorylation (Blum et al., 2000), and the implication of PI3 kinase, a classical intracellular messenger recruited by IGF-1 receptor, confirmed the involvement of the latter in the inhibition of mechanoreceptors.

Interestingly, mechanoreceptors have been shown recently to be the target of other modulatory neuropeptides such as cholecystokinin, neurotensin, and angiotensin II, which all increase

the probability of opening of the channels by an unknown mechanism (Chakfe and Bourque, 2000; Bourque et al., 2002). Our observation of the inhibition of mechanoreceptors by IGF-1 indicates that various peptides can be either activators or inhibitors of these channels, which thus integrate a variety of different signals to modulate the excitability of SON neurons.

\section{Potentiation of GlyR by IGF-1}

We found that IGF-1 also modulates GlyR, the other component of the osmosensitivity of SON neurons. IGF-1 strongly potentiated the current activated by taurine, the GlyR endogenous agonist in the HNS (Hussy et al., 2001), an effect that was completely suppressed by the GlyR antagonist strychnine. Surprisingly, potentiation of GlyR by IGF-1 was very rapid, with a maximal effect reached in $<1 \mathrm{~s}$, pointing to the possibility of a direct effect of IGF-1 on the GlyR itself. Similarly, fast potentiation of NMDA receptor by BDNF and other neurotrophins has been interpreted previously as an action at the glycine site via glycine residues of the peptides (Jarvis et al., 1997). Such an effect of IGF-1 on GlyR is unlikely, because potentiation by IGF-1 occurred in the same range of low nanomolar concentrations as inhibition of mechanoreceptors and was specifically antagonized by tyrphostin AG538. This confirmed that activation of IGF-1 receptor was necessary. Interestingly, the PI3 kinase inhibitor wortmannin did not prevent the effect of IGF-1, indicating that mechanoreceptor and GlyR modulations by IGF-1 involve different intracellular messenger pathways. No other pathway was tested, but one possibility is that a close interaction may exist between the IGF-1 receptor and GlyR, similar to that recently shown between GlyR and a close relative of the IGF- 1 receptor, the leptin receptor, which directly binds to the GlyR $\alpha$ subunit (Leite et al., 2002). A similar interaction between IGF-1 receptor and GlyR could permit rapid phosphorylation of GlyR after binding of IGF-1, which could account for the very fast kinetics of the effect. Tyrosine phosphorylation of the $\beta$ subunit of GlyR has been shown to potentiate GlyR by a twofold increase in apparent agonist affinity (Caraiscos et al., 2002), an effect remarkably similar to that induced by IGF-1 on SON neuron GlyR. Other kinases (PKC, calcium calmodulin-dependent protein kinase II) are known to also potentiate GlyR but not through a change in agonist sensitivity (Xu et al., 1996, 1999). Increased agonist affinity also implies enhanced desensitization, which could potentially result in a decreased effect of GlyR activation. However, the importance of such an effect will depend on agonist concentration and on the level of receptor desensitization. In the SON, desensitization of GlyR by taurine is partial, and our previous observations of the effect of in vivo GlyR blockade indicated sustained activation of the receptors even in the situation of enhanced taurine release (Hussy et al., 1997), suggesting that the extracellular concentration of the endogenous agonist may not reach a high enough level to induce significant desensitization.

\section{Conclusions}

Closing mechanosensitive cation channels and potentiating GlyR $\mathrm{Cl}^{-}$channels are two additive inhibitory effects by which IGF-1 will shut down electrical activity. Both are likely involved in the in vivo inhibition of neuronal firing by IGF-1, because mechanoreceptors are active at rest and will be inhibited by IGF-1, and GlyRs are constantly activated in vivo by a basal release of taurine (Hussy et al., 1997), so that an increase in apparent affinity will result in a larger GlyR current. Having both an excitatory and an inhibitory osmosensitive component probably endows the neurons with a greater sensitivity to minute change in osmotic pressure 
(Hussy et al., 2000) and offers the potential advantage of fine adaptations by differential modulation of the two systems. Interestingly, however, IGF-1 acts in a complementary manner on both components. It will be important to check whether neuropeptides that increase the activity of mechanoreceptors (Chakfe and Bourque, 2000) also inhibit GlyR channels to determine whether both systems are systematically regulated in concert or may move independently.

IGF-1 immunoreactivity is present both in neurons, which synthesize it, and in astrocytes, which display the strongest labeling; however, which cell population actually releases IGF-1 is not known. A neuronal release would imply an interesting inhibitory autocontrol by IGF-1, whereas a glial secretion would position IGF-1 as a new glia-to-neuron transmitter in the HNS, akin to taurine in the same structure (Hussy et al., 2000; Hussy, 2002). In this latter case, astrocytes would then have the intriguing capacity of releasing both the activator and the modulator of GlyR, and it would be of great interest to know whether and to what extent their release would be regulated in parallel or separately.

\section{References}

Aberg MA, Aberg ND, Palmer TD, Alborn AM, Carlsson-Skwirut C, Bang P, Rosengren LE, Olsson T, Gage FH, Eriksson PS (2003) IGF-I has a direct proliferative effect in adult hippocampal progenitor cells. Mol Cell Neurosci 24:23-40.

Aguado F, Fernandez T, Martinez-Murillo R, Rodrigo J, Cacicedo L, SanchezFranco F (1992) Immunocytochemical localization of insulin-like growth factor I in the hypothalamo-hypophyseal system of the adult rat. Neuroendocrinology 56:856-863.

Blair LA, Marshall J (1997) IGF-1 modulates N and L calcium channels in a PI3-kinase-dependent manner. Neuron 19:421-429.

Blum G, Gazit A, Levitzki A (2000) Substrate competitive inhibitors of IGF-1 receptor kinase. Biochemistry 39:15705-15712.

Bourque CW (1998) Osmoregulation of vasopressin neurons: a synergy of intrinsic and synaptic processes. Prog Brain Res 119:59-76.

Bourque CW, Voisin DL, Chakfe Y (2002) Stretch-inactivated cation channels: cellular targets for modulation of osmosensitivity in supraoptic neurons. Prog Brain Res 139:85-94.

Brooker GJ, Kalloniatis M, Russo VC, Murphy M, Werther GA, Bartlett PF (2000) Endogenous IGF-1 regulates the neuronal differentiation of adult stem cells. J Neurosci Res 59:332-341.

Caraiscos VB, Mihic SJ, MacDonald JF, Orser BA (2002) Tyrosine kinases enhance the function of glycine receptors in rat hippocampal neurons and human $\alpha 1 \beta$ glycine receptors. J Physiol (Lond) 539:495-502.

Cardona-Gomez GP, DonCarlos L, Garcia-Segura LM (2000) Insulin-like growth factor I receptors and estrogen receptors colocalize in female rat brain. Neuroscience 99:751-760.

Carro E, Nunez A, Busiguina S, Torres-Aleman I (2000) Circulating insulinlike growth factor I mediates effects of exercise on the brain. J Neurosci 20:2926-2933.

Chakfe Y, Bourque CW (2000) Excitatory peptides and osmotic pressure modulate mechanosensitive cation channels in concert. Nat Neurosci 3:572-579.

Deleuze C, Duvoid A, Hussy N (1998) Properties and glial origin of osmotic-dependent release of taurine from the rat supraoptic nucleus. J Physiol (Lond) 507:463-471.

Deleuze C, Duvoid A, Moos FC, Hussy N (2000) Tyrosine phosphorylation modulates the osmosensitivity of volume-dependent taurine efflux from glial cells in the rat supraoptic nucleus. J Physiol (Lond) 523:291-299.

de Pablo F, de la Rosa EJ (1995) The developing CNS: a scenario for the action of proinsulin, insulin and insulin-like growth factors. Trends Neurosci 18:143-150.

Fadool DA, Tucker K, Phillips JJ, Simmen JA (2000) Brain insulin receptor causes activity-dependent current suppression in the olfactory bulb through multiple phosphorylation of Kv1.3. J Neurophysiol 83:2332-2348.

Fernandez-Galaz MC, Torres-Aleman I, Garcia-Segura LM (1996) Endocrine-dependent accumulation of IGF-I by hypothalamic glia. NeuroReport 8:373-377.
Folli F, Bonfanti L, Renard E, Kahn CR, Merighi A (1994) Insulin receptor substrate-1 (IRS-1) distribution in the rat central nervous system. J Neurosci 14:6412-6422.

Gonzalez de la Vega A, Buno W, Pons S, Garcia-Calderat MS, GarciaGalloway E, Torres-Aleman I (2001) Insulin-like growth factor I potentiates kainate receptors through a phosphatidylinositol 3-kinase dependent pathway. NeuroReport 12:1293-1296.

Hellawell GO, Turner GD, Davies DR, Poulsom R, Brewster SF, Macaulay VM (2002) Expression of the type 1 insulin-like growth factor receptor is up-regulated in primary prostate cancer and commonly persists in metastatic disease. Cancer Res 62:2942-2950.

Honda K, Narita K, Murata T, Higuchi T (2002) Leptin affects the electrical activity of neurones in the hypothalamic supraoptic nucleus. Brain Res Bull 57:721-725.

Hussy N (2002) Glial cells in the hypothalamo-neurohypophysial system: key elements of the regulation of neuronal electrical and secretory activity. Prog Brain Res 139:95-112.

Hussy N, Deleuze C, Pantaloni A, Desarmenien MG, Moos F (1997) Agonist action of taurine on glycine receptors in rat supraoptic magnocellular neurones: possible role in osmoregulation. J Physiol (Lond) 502:609-621.

Hussy N, Deleuze C, Desarmenien MG, Moos FC (2000) Osmotic regulation of neuronal activity: a new role for taurine and glial cells in a hypothalamic neuroendocrine structure. Prog Neurobiol 62:113-134.

Hussy N, Bres V, Rochette M, Duvoid A, Alonso G, Dayanithi G, Moos FC (2001) Osmoregulation of vasopressin secretion via activation of neurohypophysial nerve terminals glycine receptors by glial taurine. J Neurosci 21:7110-7116.

Jarvis CR, Xiong ZG, Plant JR, Churchill D, Lu WY, MacVicar BA, MacDonald JF (1997) Neurotrophin modulation of NMDA receptors in cultured murine and isolated rat neurons. J Neurophysiol 78:2363-2371.

Jiang J, McMurtry J, Niedzwiecki D, Goldman SA (1998) Insulin-like growth factor-1 is a radial cell-associated neurotrophin that promotes neuronal recruitment from the adult songbird ependyma/subependyma. J Neurobiol 36:1-15.

Kafitz KW, Rose CR, Thoenen H, Konnerth A (1999) Neurotrophin-evoked rapid excitation through TrkB receptors. Nature 401:918-921.

Labourdette G, Sensenbrenner M (1995) Growth factors and their receptors in the central nervous system. In: Glia (Kettenman H, Ransom BR, eds), pp 441-456. New York: Oxford UP.

Le Guennec JY, Lacampagne A, Garnier D (1996) Orthophosphate salts induce calcium current recovery from blockade by gadolinium in isolated guinea-pig ventricular myocytes. Exp Physiol 81:577-585.

Leite JF, Gribble B, Randolph N, Cascio M (2002) In vitro interaction of the glycine receptor with the leptin receptor. Physiol Behav 77:565-569.

Leng G, Brown CH, Russell JA (1999) Physiological pathways regulating the activity of magnocellular neurosecretory cells. Prog Neurobiol 57:625-655.

Levine ES, Kolb JE (2000) Brain-derived neurotrophic factor increases activity of NR2B-containing $N$-methyl-D-aspartate receptors excised patches from hippocampal neurons. J Neurosci Res 62:357-362.

Lu B (2003) Acute and long-term synaptic modulation by neurotrophins. Prog Brain Res 146:135-150.

Nunez A, Carro E, Torres-Aleman I (2003) Insulin-like growth factor I modifies electrophysiological properties of rat brain stem neurons. J Neurophysiol 89:3008-3017.

O'Kusky JR, Ye P, D'Ercole AJ (2000) Insulin-like growth factor-I promotes neurogenesis and synaptogenesis in the hippocampal dentate gyrus during postnatal development. J Neurosci 20:8435-8442.

Oliet SHR, Bourque CW (1992) Properties of supraoptic magnocellular neurones isolated from the adult rat. J Physiol (Lond) 455:291-306.

Oliet SHR, Bourque CW (1994) Osmoreception in magnocellular neurosecretory cells: from single channels to secretion. Trends Neurosci 17:340-344.

Parrizas M, Gazit A, Levitzki A, Wertheimer E, LeRoith D (1997) Specific inhibition of insulin-like growth factor-1 and insulin receptor tyrosine kinase activity and biological function by tyrphostins. Endocrinology 138:1427-1433.

Reinhardt RR, Bondy CA (1994) Insulin-like growth factors cross the blood-brain barrier. Endocrinology 135:1753-1761.

Savchenko A, Kraft TW, Molokanova E, Kramer RH (2001) Growth factors 
regulate phototransduction in retinal rods by modulating cyclic nucleotide-gated channels through dephosphorylation of a specific tyrosine residue. Proc Natl Acad Sci USA 98:5880-5885.

Shanley LJ, Irving AJ, Rae MG, Ashford ML, Harvey J (2002) Leptin inhibits rat hippocampal neurons via activation of large conductance calciumactivated $\mathrm{K}^{+}$channels. Nat Neurosci 5:299-300.

Spanswick D, Smith MA, Mirshamsi S, Routh VH, Ashford ML (2000) Insulin activates ATP-sensitive $\mathrm{K}^{+}$channels in hypothalamic neurons of lean, but not obese rats. Nat Neurosci 3:757-758.

Trejo JL, Carro E, Torres-Aleman I (2001) Circulating insulin-like growth factor I mediates exercise-induced increases in the number of new neurons in the adult hippocampus. J Neurosci 21:1628-1634.

Tucker K, Fadool DA (2002) Neurotrophin modulation of voltage-gated potassium channels in rat through $\operatorname{TrkB}$ receptors is time and sensory experience dependent. J Physiol (Lond) 542:413-429.
Voisin DL, Bourque CW (2002) Integration of sodium and osmosensory signals in vasopressin neurons. Trends Neurosci 25:199-205.

Wang YT, Linden DJ (2000) Expression of cerebellar long-term depression requires postsynaptic clathrin-mediated endocytosis. Neuron 25: 635-647.

Xu TL, Nabekura J, Akaike N (1996) Protein kinase C-mediated enhancement of glycine response in rat sacral dorsal commissural neurones by serotonin. J Physiol (Lond) 496:491-501.

Xu TL, Li JS, Jin YH, Akaike N (1999) Modulation of the glycine response by $\mathrm{Ca}^{2+}$-permeable AMPA receptors in rat spinal neurones. J Physiol (Lond) 514:701-711.

Zhou X, Herman JP, Paden CM (1999) Evidence that IGF-I acts as an autocrine/paracrine growth factor in the magnocellular neurosecretory system: neuronal synthesis and induction of axonal sprouting. Exp Neurol 159:419-432. 